\title{
Experience with Thoracic Aortic Stent-Grafting at the Royal Brisbane and Women's Hospital: Outcomes from the First Decade*
}

\author{
Michel R. Hoenig' ${ }^{1 \#}$, Jason Jenkins ${ }^{1}$, Nicholas Boyne ${ }^{1}$, Allan Kruger ${ }^{1}$, Philip J. Walker ${ }^{1,2}$ \\ ${ }^{1}$ Department of Vascular Surgery, Royal Brisbane \& Women's Hospital, Herston, Australia \\ ${ }^{2}$ Discipline of Surgery, School of Medicine, Centre for Clinical Research, University of Queensland, Herston, Australia \\ Email: \#drmhoenig@yahoo.com.au
}

Received April 15, 2012; revised May 20, 2012; accepted June 18, 2012

\begin{abstract}
Objectives: To describe thoracic endovascular aortic repair (TEVAR) outcomes at the Royal Brisbane and Women's Hospital between 2001-2010. Design: Prospective cohort study. Results: We successfully treated 95 of 97 patients for a 98\% procedural success rate. Of the treated patients, 68 (72\%) were males and mean age was $61 \pm 17$ years. Average follow up was $3.6 \pm 2.0$ years. Pathologies treated were: dissection $(n=35)$, aneurysmal disease $(n=32)$, traumatic disease $(n=19)$, coarctation $(n=5)$ and miscellaneous $(n=4)$. There was one peri-procedural myocardial infarction. Renal complications occurred in 7 patients (3 with doubling creatinine and 4 requiring temporary renal replacement therapy). Stroke occurred in 2 patients and paresis in 2 patients (permanent in one). Six patients died during index hospitalization and 17 deaths occurred during follow-up, 2 of which were confirmed secondary to aortic pathology. Age (HR 1.08 per year, $\mathrm{p}<0.01$ ) and ASA class (HR 2.2 per class, $\mathrm{p}=0.02$ ) were independently associated with mortality. There were 25 re-interventions in 22 patients. Eighteen of these re-interventions in 16 patients were related to the management of complications of TEVAR of which 13 were for endoleaks; eight type I, four type II, one type III. Conclusion: TEVAR can be used to treat thoracic aortic pathology but questions remain regarding long-term durability.
\end{abstract}

Keywords: Aorta; Stents; Surgery

\section{Introduction}

Since its introduction to treat descending thoracic aneurysmal disease and aortic ulcers in 1994 [1], thoracic endovascular aortic repair (TEVAR) is being increasingly utilized to treat the entire spectrum of thoracic aortic diseases. A recent systematic review of 2828 patients from 38 non-randomized studies comparing TEVAR to open surgery for the treatment of degenerative aneurysm, dissection, traumatic rupture, intramural hematoma or penetrating ulcers showed stent-grafting to be associated with lower short-term mortality and complications rates compared to open repair [2]. However, TEVAR case series typically have limited follow up and mortality benefits compared to traditional open repair are not sustained in the longer term [2]. In the absence of evidence from randomized trials, outcomes data is relevant to establish benchmarks and to allow indirect comparison to open repair. Herein we report the TEVAR experience at The Royal Brisbane and Women's Hospital with an emphasis on need for reintervention and survival on late follow-up.

"Disclosure: None.

${ }^{\#}$ Corresponding author.

\section{Methods}

This case series describes the results from our first decade of TEVAR. This includes 97 patients seen between 2001-2010 and considered for TEVAR. Open thoracic aortic surgery was undertaken at an adjacent institution with on-site cardiac surgery services. Unfortunately, we do not have an open surgery series to serve as a comparator group. This study was approved by our Hospital Research Ethics Committee. SPSS was used for statistical analysis.

\section{Patient Characteristics}

Of the 97 patients who were considered for TEVAR at our centre, 95 were successfully treated for a $98 \%$ primary procedural success rate. The two procedural failures were related to inability to track the stent-graft secondary to iliac or aortic tortuosity. Table 1 summarizes the aortic pathologies treated in the 95 patients who underwent a successful procedure stratified to acuity of intervention; acute denotes intervention within 24 hours of presentation, subacute within $1-14$ days and chronic after 2 weeks. Aortic dissection, aneurysmal disease and 
Table 1. Overview of the aortic pathologies treated with TEVAR and acuity of intervention.

\begin{tabular}{|c|c|c|c|c|c|}
\hline \multirow[b]{2}{*}{ Pathology } & \multirow[b]{2}{*}{ Subtype } & \multicolumn{3}{|c|}{ Acuity of Intervention (n) } & \multirow[b]{2}{*}{ Total Number per Subtype } \\
\hline & & $\begin{array}{l}\text { Acute } \\
(<24 \mathrm{~h})\end{array}$ & $\begin{array}{l}\text { Sub-Acute } \\
(1-14 \text { d) }\end{array}$ & $\begin{array}{l}\text { Chronic } \\
\text { (>14 d) }\end{array}$ & \\
\hline \multirow{7}{*}{$\begin{array}{l}\text { Type B Aortic Dissection/ } \\
\text { Acute Aortic Syndromes } \\
\mathrm{N}=35\end{array}$} & Uncomplicated Dissection & 0 & 1 & 8 & 9 \\
\hline & Dissection with False Lumen Enlargement & 0 & 0 & 11 & 11 \\
\hline & Dissection with Malperfusion & 0 & 1 & 2 & 3 \\
\hline & Dissection with Persistent Pain & 1 & 1 & 0 & 2 \\
\hline & Ruptured Dissection & 5 & 0 & 0 & 5 \\
\hline & Intramural Hematoma & 0 & 1 & 0 & 1 \\
\hline & Penetrating Ulcer & 2 & 2 & 0 & 4 \\
\hline \multirow{5}{*}{$\begin{array}{l}\text { Aneurysmal Disease } \\
\mathrm{N}=32\end{array}$} & Non-Ruptured Degenerative Aneurysm & 0 & 1 & 22 & 23 \\
\hline & Ruptured Degenerative Aneurysm & 6 & 0 & 0 & 6 \\
\hline & Marfans Thoracic Aneurysm & 0 & 0 & 1 & 1 \\
\hline & Mycotic Thoracic Aneurysm & 1 & 0 & 0 & 1 \\
\hline & Takayasu’s Aneurysm & 0 & 0 & 1 & 1 \\
\hline \multirow{3}{*}{$\begin{array}{l}\text { Traumatic Aortic } \\
\text { Disease } \\
\mathrm{N}=19\end{array}$} & Traumatic Aortic Tear & 12 & 2 & 0 & 14 \\
\hline & Traumatic Aortic Rupture & 1 & 0 & 0 & 1 \\
\hline & Pseudoaneurysm Post-Trauma & 1 & 0 & 3 & 4 \\
\hline $\begin{array}{l}\text { Post-Ductal Aortic } \\
\text { Coarctation } \\
\mathrm{N}=5\end{array}$ & Pseudoaneurysm Post Open Coartation Repair & 0 & 0 & 5 & 5 \\
\hline \multirow{3}{*}{$\begin{array}{l}\text { Miscellaneous } \\
\mathrm{N}=4\end{array}$} & Aorto-Oesophageal Fistula & 2 & 1 & 0 & 3 \\
\hline & Treatment of Left Subclavian Aneurysm & 0 & 0 & 1 & 1 \\
\hline & Total & 35 & 9 & 51 & 95 \\
\hline
\end{tabular}

traumatic aortic disease together comprised the bulk of pathology treated; $n=89$ (94\%). Table 2 summarizes the characteristics of the treated patients. Males comprised the majority of the cohort (72\%). Patients with traumatic aortic disease, aortic coarctation or miscellaneous aortic pathology were younger than those with aneurysmal disease or dissection (51 vs $65 \mathrm{p}<0.001$ ) and were less likely to have clinically-apparent atherosclerosis (11\% vs $39 \%, \mathrm{p}<0.001)$ or renal failure at baseline $(0 \%$ vs $13 \%$, $\mathrm{p}<0.001)$.

\section{Results}

\subsection{Procedure Details}

Table 3 summarizes the procedural details of the included patients. All patients received commercially-available stentgrafts. We deployed 158 endovascular devices in 95 patients for an average of 1.7 devices per patient (range 1 4). Femoral access was sufficient in $94 \%$ of cases with only 2 patients requiring retroperitoneal iliac exposure and 4 requiring a conduit (3 iliac, one aortic). A zone 3 or distal landing was possible in 73 of the 95 patients (77\%) with more proximal landing zones required in the remaining 22 (23\%) of patients. Five patients with the stent grafting landing in zone 1 underwent adjunctive/ pre-operative left carotid revascularization. Of the 17 patients with stent graft landing zone 2, 8 received adjunctive left subclavian artery revascularization with the majority of the 9 patients not revascularized being acute presentations (7 of 9 or $78 \%$ ). The average length of stay after the procedure was 15 days (range 0 to 74) with a median of 10 .

\subsection{Post-Operative Morbidity and Mortality}

Complications during index hospitalization are summarized in Table 4. Six patients (6\%) died during the index hospitalization. Sixteen patients (16\%) required re-operation during the index hospitalization. Deaths and re-interventions are detailed in the next section. Two patients had an access complication; one iliac artery ruptured after sheath removal and there was one case of femoral artery thrombus. Cardiac complications occurred in 8 patients and were predominantly arrhythmias. One patient had angina and one peri-operative myocardial infarction occurred. Pulmonary complications occurred in 9 patients and included 4 cases of respiratory failure, one case of re-intubation and one pulmonary embolism as detailed in Table 4. 
Table 2. Baseline characteristics and comorbid conditions of the cohort.

\begin{tabular}{|c|c|c|c|c|c|}
\hline \multirow{2}{*}{ Variable } & \multicolumn{5}{|c|}{ Aortic Pathology } \\
\hline & Dissection $\mathrm{n}=35$ & Aneurysmal n = 32 & Traumatic $\mathrm{n}=19$ & Coarctation $\mathrm{n}=5$ & Miscellaneous $n=4$ \\
\hline Age (mean \pm SD) & $62 \pm 15$ & $68 \pm 14$ & $47 \pm 16$ & $58 \pm 20$ & $59 \pm 21$ \\
\hline Sex n, (\% male) & $25(71)$ & $22(69)$ & 15 (79) & $3(60)$ & $3(75)$ \\
\hline Year of Surgery (mean \pm SD) & $2006 \pm 2$ & $2006 \pm 1$ & $2006 \pm 2$ & $2005 \pm 1$ & $2005 \pm 2$ \\
\hline Hypertensive n, (\%) & $28(80)$ & $25(78)$ & $3(16)$ & $4(80)$ & $1(25)$ \\
\hline Diabetic n, (\%) & $1(3)$ & $2(6)$ & $1(5)$ & $0(0)$ & $1(25)$ \\
\hline Peripheral Vascular Disease n, (\%) & $0(0)$ & $6(19)$ & $1(5)$ & $0(0)$ & $0(0)$ \\
\hline Ischemic Heart Disease n, (\%) & $8(23)$ & $11(34)$ & $2(11)$ & $1(20)$ & $0(0)$ \\
\hline History of Stroke n, (\%) & $3(9)$ & $5(16)$ & $1(5)$ & $1(20)$ & $0(0)$ \\
\hline History of TIA n, (\%) & $0(0)$ & $2(6)$ & $1(5)$ & $0(0)$ & $0(0)$ \\
\hline Congestive Heart Failure n, (\%) & $0(0)$ & $2(6)$ & $0(0)$ & $0(0)$ & $0(0)$ \\
\hline Hypercholesterolemia n, (\%) & $8(23)$ & $14(44)$ & $2(10)$ & $2(40)$ & $0(0)$ \\
\hline Chronic Obstructive Pulmonary Disease n, (\%) & $5(14)$ & $10(31)$ & $1(5)$ & $1(25)$ & $0(0)$ \\
\hline Asthma n, (\%) & $3(9)$ & $2(6)$ & $2(10)$ & $0(0)$ & $2(50)$ \\
\hline baseline Creatinine (mean \pm SD) & $0.18 \pm 0.24$ & $0.11 \pm 0.07$ & $0.08 \pm 0.04$ & $0.08 \pm 0.01$ & $0.09 \pm 0.01$ \\
\hline Renal Failure n, (\%) & $4(11)$ & $5(16)$ & $0(0)$ & $0(0)$ & $0(0)$ \\
\hline Dialysis at Baseline n, (\%) & $0(0)$ & $1(3)$ & $0(0)$ & $0(0)$ & $0(0)$ \\
\hline \multicolumn{6}{|l|}{ Smoking n, (\%) } \\
\hline Current & $10(29)$ & $5(16)$ & $3(16)$ & $0(0)$ & $2(50)$ \\
\hline Former & $20(57)$ & $22(68)$ & $11(58)$ & $1(20)$ & $2(50)$ \\
\hline Never & $5(14)$ & $5(16)$ & $5(26)$ & $4(80)$ & $0(0)$ \\
\hline \multicolumn{6}{|l|}{ ASA Functional Class } \\
\hline Class I & $0(0)$ & $0(0)$ & $2(11)$ & $0(0)$ & $0(0)$ \\
\hline Class II & $4(11)$ & $4(13)$ & $0(0)$ & $2(40)$ & $1(25)$ \\
\hline Class III & $16(46)$ & $20(62)$ & $10(53)$ & $3(60)$ & $1(25)$ \\
\hline Class IV & $15(43)$ & $8(25)$ & 7 (37) & $0(0)$ & $1(25)$ \\
\hline Class V & $0(0)$ & $0(0)$ & $0(0)$ & $0(0)$ & $1(25)$ \\
\hline Symptomatic Disease n, (\%) & $15(43)$ & $13(41)$ & $14(74)$ & $1(20)$ & $3(75)$ \\
\hline Diameter of Treated Aneurysms (mean \pm SD) & $71 \pm 10$ & $51 \pm 14$ & $29 \pm 13$ & $66 \pm 29$ & N/A \\
\hline Preoperative Hemoglobin (mg/dl) & $128 \pm 14$ & $128 \pm 17$ & $129 \pm 20$ & $142 \pm 8$ & $121 \pm 29$ \\
\hline
\end{tabular}

Table 3. Procedural details of the 95 successful thoracic endovascular procedures.

\begin{tabular}{|c|c|c|c|c|c|}
\hline \multirow{2}{*}{ Variable } & \multicolumn{5}{|c|}{ Aortic Pathology } \\
\hline & Dissection $\mathrm{n}=35$ & Aneurysmal $\mathrm{n}=32$ & Traumatic $\mathrm{n}=19$ & Coarctation $\mathrm{n}=5$ & Miscellaneous $\mathrm{n}=4$ \\
\hline \multicolumn{6}{|l|}{ Anaesthetic n, (\%) } \\
\hline General & $35(100)$ & $29(91)$ & $19(100)$ & $5(100)$ & $4(100)$ \\
\hline Epidural or Spinal & $0(0)$ & $3(9)$ & $0(0)$ & $0(0)$ & $0(0)$ \\
\hline \multicolumn{6}{|l|}{ Graft Type n, (\%) } \\
\hline Talent & $9(26)$ & $8(25)$ & $7(37)$ & $1(20)$ & $2(50)$ \\
\hline Zenith & $23(66)$ & $22(69)$ & $12(63)$ & $0(0)$ & $2(50)$ \\
\hline Valiant & $3(8)$ & $2(6)$ & $0(0)$ & $4(80)$ & $0(0)$ \\
\hline Operative Time, Minutes (mean \pm SD) & $143 \pm 37$ & $150 \pm 79$ & $124 \pm 51$ & $169 \pm 48$ & $181 \pm 100$ \\
\hline \multicolumn{6}{|l|}{ Access n, (\%) } \\
\hline Iliac & $0(0)$ & $0(0)$ & $2(11)$ & $0(0)$ & $0(0)$ \\
\hline Iliac Conduit & $3(9)$ & $0(0)$ & $0(0)$ & $0(0)$ & $0(0)$ \\
\hline
\end{tabular}




\section{Continued}

\begin{tabular}{|c|c|c|c|c|c|}
\hline Femoral & $32(91)$ & $31(97)$ & 17 (89) & $5(100)$ & $4(100)$ \\
\hline Aortic Conduit & $0(0)$ & $1(3)$ & $0(0)$ & $0(0)$ & $0(0)$ \\
\hline \multicolumn{6}{|l|}{ Landing Zone n, (\%) } \\
\hline Zone 1 & $3(9)$ & $1(3)$ & $0(0)$ & $1(20)$ & $0(0)$ \\
\hline Zone 2 & $7(20)$ & $6(19)$ & $1(5)$ & $2(40)$ & $1(25)$ \\
\hline Zone 3 & $23(66)$ & $25(78)$ & $18(95)$ & $2(40)$ & $3(75)$ \\
\hline Zone 4 & $2(6)$ & $0(0)$ & $0(0)$ & $0(0)$ & $0(0)$ \\
\hline \multicolumn{6}{|l|}{ Access Closure n, (\%) } \\
\hline Direct & $35(100)$ & $31(97)$ & $19(100)$ & $5(100)$ & $3(75)$ \\
\hline Patch & $0(0)$ & $1(3)$ & $0(0)$ & $0(0)$ & $1(25)$ \\
\hline Blood Loss, ml (mean \pm SD) & $23 \pm 97$ & $31 \pm 106$ & $79 \pm 334$ & $40 \pm 89$ & $3750 \pm 7500$ \\
\hline Units of Blood Transfused (mean \pm SD) & $0.5 \pm 1.6$ & $1.3 \pm 5.8$ & $0.7 \pm 1.7$ & $0 \pm 0$ & $13 \pm 26$ \\
\hline FFP Units (mean \pm SD) & $0.3 \pm 1.1$ & $0.4 \pm 2.1$ & $0.5 \pm 1.1$ & $0 \pm 0$ & $5.5 \pm 11$ \\
\hline Platelet Units (mean \pm SD) & $0 \pm 0$ & $0.3 \pm 1.4$ & $0 \pm 0$ & $0 \pm 0$ & $6 \pm 12$ \\
\hline $\begin{array}{l}\text { Intraoperative Colloid volume, ml } \\
\text { (mean } \pm \text { SD) }\end{array}$ & $80 \pm 300$ & $140 \pm 560$ & $180 \pm 380$ & $100 \pm 220$ & $250 \pm 500$ \\
\hline $\begin{array}{l}\text { Intraoperative Crystalloid Volume, ml } \\
\text { (mean } \pm \text { SD) }\end{array}$ & $1600 \pm 1200$ & $1600 \pm 1000$ & $2000 \pm 1400$ & $2200 \pm 450$ & $2750 \pm 2900$ \\
\hline Number of Stents Used (mean \pm SD) & $1.6 \pm 0.9$ & $2.1 \pm 0.8$ & $1.1 \pm 0.2$ & $2.0 \pm 0.7$ & $2.0 \pm 0.8$ \\
\hline \multicolumn{6}{|c|}{$\begin{array}{l}\text { Adjunct Arch (Subclavian or Carotid) Bypass } \\
\text { Procedure }\end{array}$} \\
\hline Left Subclavian Revasc & $1(3)$ & $5(16)$ & $0(0)$ & $1(20)$ & $1(25)$ \\
\hline Carotid Revasc & $3(9)$ & $1(3)$ & $0(0)$ & $1(20)$ & $0(0)$ \\
\hline \multicolumn{6}{|l|}{ Post-Operative Care } \\
\hline ICU & $15(43)$ & $11(34)$ & $15(79)$ & $2(40)$ & $2(50)$ \\
\hline HDU & $20(57)$ & $20(63)$ & $3(16)$ & $3(60)$ & $2(50)$ \\
\hline Ward & $0(0)$ & $1(3)$ & $1(5)$ & $0(0)$ & $0(0)$ \\
\hline Days in ICU (mean \pm SD) & $1.9 \pm 2.9$ & $1.8 \pm 4.2$ & $5.0 \pm 5.4$ & $1.2 \pm 2.2$ & $1.8 \pm 2.9$ \\
\hline $\begin{array}{l}\text { Days of Post-Operative Hospitalization } \\
\text { (mean } \pm \text { SD) }\end{array}$ & $14 \pm 14$ & $13 \pm 15$ & $20 \pm 12$ & $8 \pm 4$ & $27 \pm 14$ \\
\hline
\end{tabular}

Table 4. Post-operative morbidity and mortality.

\begin{tabular}{|c|c|c|c|c|c|}
\hline \multirow{2}{*}{ Variable n, (\%) } & \multicolumn{5}{|c|}{ Aortic Pathology } \\
\hline & Dissection $\mathrm{n}=35$ & Aneurysmal $n=32$ & Traumatic $\mathrm{n}=19$ & Coarctation $\mathrm{n}=5$ & Miscellaneous $n=4$ \\
\hline Death During Index Hospitalization & $2(6)$ & $3(9)$ & $1(5)$ & $0(0)$ & $0(0)$ \\
\hline Re-Operation During Index Hospitalization & $6(17)$ & $6(19)$ & $2(11)$ & $1(20)$ & $1(25)$ \\
\hline Access Complications & $0(0)$ & $1(3)$ & $1(5)$ & $0(0)$ & $0(0)$ \\
\hline Required Re-Admission to ICU & $3(9)$ & $1(3)$ & $0(0)$ & $0(0)$ & $0(0)$ \\
\hline Cardiac Complications & $3(9)$ & $5(16)$ & $0(0)$ & $0(0)$ & $0(0)$ \\
\hline Angina & $1(3)$ & $0(0)$ & $0(0)$ & $0(0)$ & $0(0)$ \\
\hline Myocardial Infarction & $0(0)$ & $1(3)$ & $0(0)$ & $0(0)$ & $0(0)$ \\
\hline CCF & $0(0)$ & $1(3)$ & $0(0)$ & $0(0)$ & $0(0)$ \\
\hline Cardiac Arrest & $1(3)$ & $1(3)$ & $0(0)$ & $0(0)$ & $0(0)$ \\
\hline Atrial Fibrillation/SVT & $1(3)$ & $2(6)$ & $0(0)$ & $1(20)$ & $1(25)$ \\
\hline Pulmonary Complication & $6(17)$ & $3(9)$ & $0(0)$ & $0(0)$ & $0(0)$ \\
\hline Atelactasis & $0(0)$ & $1(3)$ & $0(0)$ & $0(0)$ & $0(0)$ \\
\hline Pneumonia & $3(9)$ & $1(3)$ & $0(0)$ & $1(20)$ & $0(0)$ \\
\hline
\end{tabular}




\begin{tabular}{|c|c|c|c|c|c|}
\hline \multicolumn{6}{|l|}{ Continued } \\
\hline Resp Failure & $2(6)$ & $1(3)$ & $1(5)$ & $0(0)$ & $0(0)$ \\
\hline Re-Intubation & $0(0)$ & $0(0)$ & $1(5)$ & $0(0)$ & $0(0)$ \\
\hline Pulmonary Embolism & $1(3)$ & $0(0)$ & $0(0)$ & $0(0)$ & $0(0)$ \\
\hline Gastrointestinal Complications & $0(0)$ & $2(6)$ & $1(5)$ & $0(0)$ & $0(0)$ \\
\hline Ileus & $0(0)$ & $1(3)$ & $0(0)$ & $0(0)$ & $0(0)$ \\
\hline Ischemic Colitis & $0(0)$ & $1(3)$ & $0(0)$ & $0(0)$ & $0(0)$ \\
\hline Ischemic Hepatitis & $0(0)$ & $0(0)$ & $1(5)$ & $0(0)$ & $0(0)$ \\
\hline Renal Complications & $2(6)$ & $4(12)$ & $1(5)$ & $0(0)$ & $0(0)$ \\
\hline Acute Renal Failure & $2(6)$ & $1(3)$ & $0(0)$ & $0(0)$ & $0(0)$ \\
\hline ARF Requiring Dialysis & $0(0)$ & $3(9)$ & $1(5)$ & $0(0)$ & $0(0)$ \\
\hline Cerebrovascular Complications & $8(23)$ & $0(0)$ & $0(0)$ & $0(0)$ & $0(0)$ \\
\hline Stroke & $2(6)$ & $0(0)$ & $0(0)$ & $0(0)$ & $0(0)$ \\
\hline Confusion & $6(17)$ & $4(12)$ & $2(10)$ & $1(20)$ & $0(0)$ \\
\hline Paresis & $1(3)$ & $1(3)$ & $0(0)$ & $0(0)$ & $0(0)$ \\
\hline Requiring Transfusion & $2(6)$ & $3(9)$ & $1(5)$ & $0(0)$ & $1(25)$ \\
\hline Headache Related to CSF Drain & $3(9)$ & $0(0)$ & $0(0)$ & $0(0)$ & $0(0)$ \\
\hline Hemothorax & $2(6)$ & $0(0)$ & $0(0)$ & $0(0)$ & $0(0)$ \\
\hline
\end{tabular}

Ischemic colitis occurred in one patient with aortic dissection who had malperfusion of the superior mesenteric artery and ischemic hepatitis secondary to hypotension occurred in one patient with traumatic aortic disruption. The celiac trunk was not covered in any of our interventions. Acute renal failure occurred in 7 patients, 3 of whom had a doubling of baseline creatinine and 4 requiring temporary renal replacement therapy. Stroke occurred in 2 patients and paresis in 2. Of the 2 cases of paresis, one case resolved and the other progressed to permanent paraplegia.

\subsection{Mortality Outcomes}

The cohort was followed for an average of $3.6 \pm 2.0$ years (range 0 - 9.1). Of the 95 treated patients, there were 17 deaths (17\%) with 6 of these occurring during the index hospitalization. By 30 days, there were 4 mortalities (4\%) and by one year, there were 12 mortalities (13\%). The deaths in the cohort are summarized in Table $\mathbf{5}$ and Figure 1 displays a Kaplan Meier curve for the cohort as a whole. Of the 17 mortalities over the average follow up of 3.6 years, only 2 could be confirmed as being related to thoracic aortic pathology (aneurysm rupture); of the remaining 15, 4 were cardiac, 2 were multi-organ dysfunction, one was cerebrovascular and 8 were unknown. On Cox proportional hazard ratio analysis, the following variables emerged as being independently associated with an increased hazard for death: age (HR 1.08 per year, p < 0.01) and American Society of Anesthesiologists (ASA) physical status class (HR 2.2 for every increment in class, $\mathrm{p}=0.02$ ). Notably, a history of ischemic heart disease, acuity of intervention, presence of symptoms, spinal cord

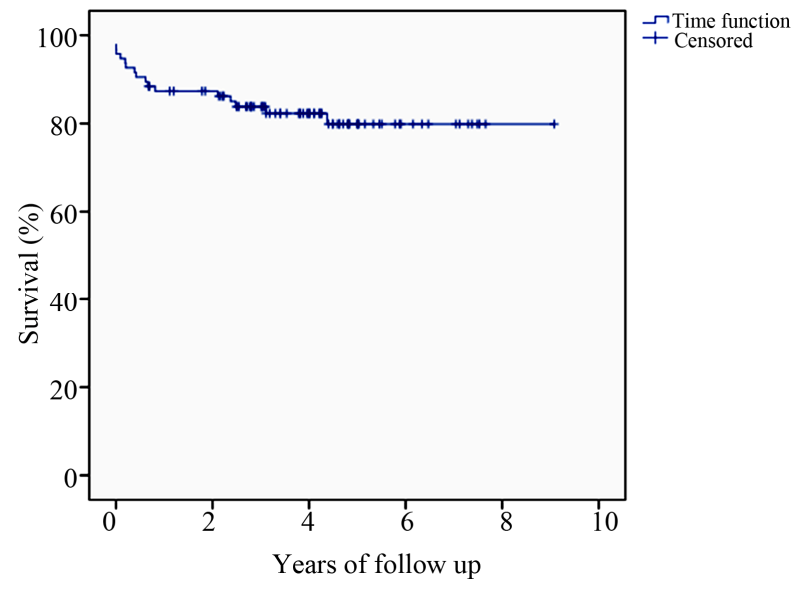

Figure 1. Mortality after thoracic stent-grafting.

ischemia, pre- or post-procedural renal impairment or need for reintervention were not associated with a mortality hazard in our cohort.

\subsection{Reinterventions}

Twenty five interventions in twenty-two patients (23\% of the cohort) were required during follow up (average 3.6 years) and are summarized in Table 6. All but seven of these interventions were related to the index stent-graft procedure. Four of the reinterventions unrelated to the index stent-graft procedure were for aortic pathology in an area remote to the initial stent-graft. Two patients had thoracic hematoma evacuation and one patient required a hemicolectomy to treat ischemic bowel from dynamic obstruction of the superior mesenteric artery in the setting of complicated dissection. This leaves 18 reinterven- 
Table 5. Patient mortality summary.

\begin{tabular}{|c|c|c|c|c|c|c|c|c|c|}
\hline Patient & Pathology & $\begin{array}{l}\text { Acuity of } \\
\text { Intervention }\end{array}$ & $\begin{array}{l}\text { Aneurysm } \\
\text { Size (mm) }\end{array}$ & $\begin{array}{l}\text { Time From } \\
\text { Procedure }\end{array}$ & Reinterventions & $\begin{array}{l}\text { Death } \\
\text { During Index } \\
\text { Hospitalization? }\end{array}$ & Autopsy & $\begin{array}{l}\text { Age at } \\
\text { death }\end{array}$ & $\begin{array}{l}\text { Cause } \\
\text { of Death }\end{array}$ \\
\hline 1 & $\begin{array}{l}\text { Ruptured Aortic } \\
\text { Dissection with } \\
\text { False Aneurysm }\end{array}$ & Acute & 80 & 0 day & None & Yes & Yes & 75 & $\begin{array}{c}\text { Proximal } \\
\text { extension with } \\
\text { cardiac } \\
\text { tamponade }\end{array}$ \\
\hline 2 & $\begin{array}{l}\text { Degenerative } \\
\text { Aneurysm }\end{array}$ & Acute & 57 & 0 day & $\begin{array}{l}\text { Day 0: Repeat angiography } \\
\text { showing distal leak of contrast } \\
\text { but not into aneurysm sac } \\
\text { treated with extension graft. }\end{array}$ & Yes & No & 67 & $\begin{array}{c}\text { Acute } \\
\text { myocardial } \\
\text { infarction }\end{array}$ \\
\hline 3 & $\begin{array}{l}\text { Ruptured Aortic } \\
\text { Dissection with } \\
\text { False Aneurysm }\end{array}$ & Acute & 60 & 1 day & None & Yes & Yes & 80 & $\begin{array}{c}\text { Sudden cardiac } \\
\text { death }\end{array}$ \\
\hline 4 & $\begin{array}{l}\text { Type B Aortic } \\
\text { Dissection }\end{array}$ & Acute & - & 3 days & $\begin{array}{l}\text { Day 1: Ischemic bowel. } \\
\text { Extended right hemicolectomy } \\
\text { and short bowel resection. }\end{array}$ & Yes & No & 45 & $\begin{array}{l}\text { Multi-organ } \\
\text { failure }\end{array}$ \\
\hline 5 & $\begin{array}{l}\text { Ruptured } \\
\text { Degenerative } \\
\text { Aneurysm }\end{array}$ & Acute & 57 & 34 days & $\begin{array}{l}\text { Day 0: Left thoracoscopic } \\
\text { procedure for drainage of } \\
\text { haematoma. }\end{array}$ & Yes & No & 81 & $\begin{array}{c}\text { Sudden cardiac } \\
\text { death }\end{array}$ \\
\hline 6 & $\begin{array}{l}\text { Degenerative } \\
\text { Aneurysm }\end{array}$ & Chronic & 42 & 2.3 months & None & No & No & 79 & $\begin{array}{c}\text { Thoracic } \\
\text { aneurysm } \\
\text { rupture }\end{array}$ \\
\hline 7 & $\begin{array}{l}\text { Degenerative } \\
\text { Aneurysm }\end{array}$ & Acute & 57 & 2.4 months & $\begin{array}{l}\text { Day 3: Access complication; } \\
\text { thrombus in the left common } \\
\text { femoral artery treated with } \\
\text { thrombectomy, endarterec- } \\
\text { tomy \& profundaplasty. }\end{array}$ & Yes & No & 71 & $\begin{array}{l}\text { Multiple organ } \\
\text { failure }\end{array}$ \\
\hline 8 & $\begin{array}{l}\text { Ruptured Type B } \\
\text { Aortic Dissection }\end{array}$ & Acute & - & 4.6 months & Day 28: Extension stent-graft. & No & No & 74 & Unknown \\
\hline 9 & $\begin{array}{l}\text { Degenerative } \\
\text { Aneurysm }\end{array}$ & Chronic & 25 & 5 months & $\begin{array}{l}\text { None; Patient developed } \\
\text { spinal cord ischemia post-op. }\end{array}$ & No & No & 76 & Unknown \\
\hline 10 & $\begin{array}{l}\text { Chronic Type B } \\
\text { Dissection }\end{array}$ & Chronic & - & 7.4 months & None & No & No & 81 & Unknown \\
\hline 11 & $\begin{array}{l}\text { Chronic Type B } \\
\text { Dissection with } \\
\text { false aneurysm }\end{array}$ & Chronic & 76 & 7.9 months & None & No & No & 78 & Stroke \\
\hline 12 & $\begin{array}{l}\text { Aorto-Esophageal } \\
\text { Fistula }\end{array}$ & Sub-acute & - & 9.5 months & None & No & No & 65 & Unknown \\
\hline 13 & $\begin{array}{l}\text { Chronic Type B } \\
\text { Dissection }\end{array}$ & Chronic & - & 2.1 years & None & No & No & 70 & Unknown \\
\hline 14 & $\begin{array}{l}\text { Degenerative } \\
\text { Anuerysm }\end{array}$ & Chronic & 49 & 2.4 years & None & No & No & 77 & $\begin{array}{c}\text { Acute } \\
\text { myocardial } \\
\text { infarction }\end{array}$ \\
\hline 15 & $\begin{array}{l}\text { Chronic Type B } \\
\text { Dissection }\end{array}$ & Chronic & - & 2.5 years & None & No & No & 73 & Unknown \\
\hline 16 & $\begin{array}{l}\text { Degenerative } \\
\text { Anuerysm }\end{array}$ & Chronic & 36 & 3.1 years & None & No & No & 76 & Unknown \\
\hline 17 & $\begin{array}{l}\text { Degenerative } \\
\text { Anuerysm }\end{array}$ & Chronic & 82 & 4.4 years & None & No & No & 78 & Unknown \\
\hline
\end{tabular}


Table 6. Re-interventions in the thoracic stent-graft cohort.

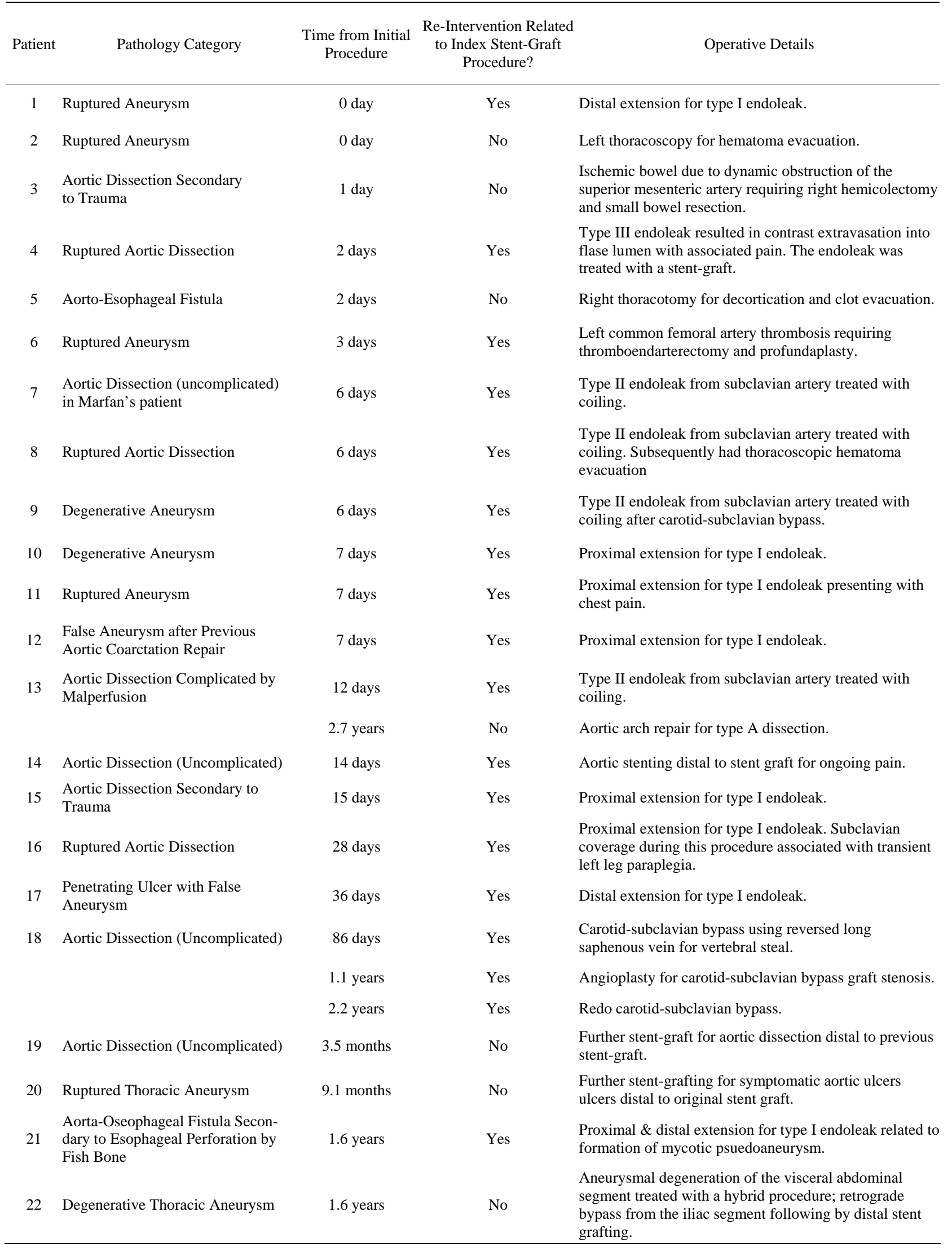


tions in 16 patients ( $16 \%$ of the cohort) that were related to the management of complications of the index-stent graft, 13 of which were for endoleak. The mean time to reintervention was 52 days (range 0 days to 1.7 years). Of these 18 reinterventions, 8 were for type I endoleak, 4 were type II endoleak, one for a type III endoleak, one was to treat an access complication, one involved aortic stenting for ongoing pain in the setting of dissection and one patient required 3 procedures for left subclavian artery revascularization to treat symptomatic subclavian coverage. Figure 2 illustrates the timing of reinterventions related to the index stent-graft procedure.

\section{Discussion}

The rapid uptake of TEVAR to treat thoracic aortic pathology has been spurred by the widespread availability of factory-made stent grafts that replaced "home-made" grafts and reports of reduced short-term mortality with TEVAR compared to open surgery. A recent systematic review of 2,828 patients from 38 non-randomized studies comparing TEVAR to open surgery showed TEVAR to be associated with a lower 30-day mortality, paraplegia risk, cardiac complication rate, renal dysfunction, pneumonia, reoperation for bleeding and hospital length of stay compared to open repair [2]. Thirty day mortality was $5.8 \%$ in the stent-graft group and $13.9 \%$ in the open surgery group and the risks of permanent paraplegia were $1.4 \%$ and $4.9 \%$ respectively (all $\mathrm{p}<0.01$ ). Interestingly, stent-grafting was not associated with a reduced incidence of stroke, acute myocardial infarction, ischemic complications (gut or limb), aortoesophageal fistula, laryngeal or phrenic nerve injury or wound complications in this systematic review. Surprisingly, the need for re-intervention was similar in the two groups. However, in this systematic review, reporting on the incidence of endoleaks was incomplete. From the few studies that did

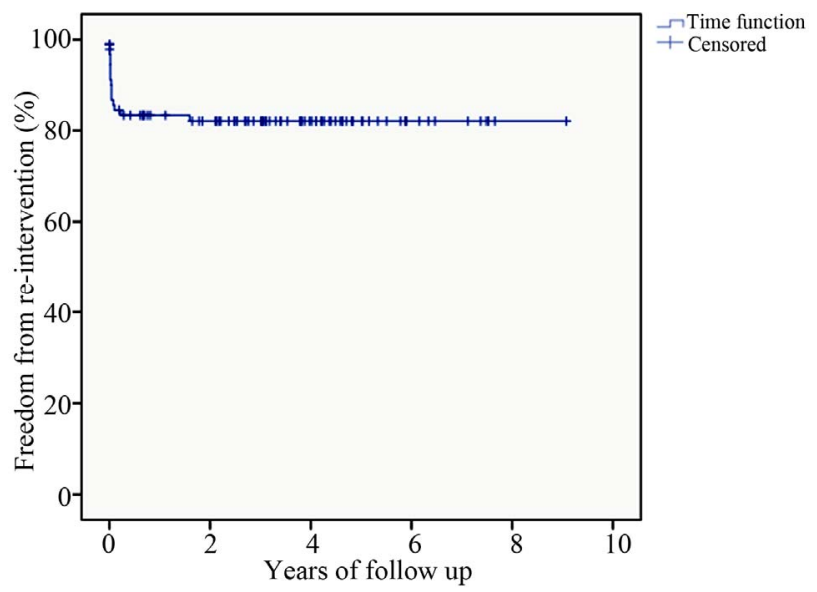

Figure 2. Freedom from re-intervention after thoracic stentgrafting. report this outcome, endoleak incidence (Type I and Type II) was $12.1 \%$. We re-intervened on 13 patients (14\%) with endoleak which is concordant with this figure. Importantly, the mortality benefit of stent-grafting was no longer significant at one year $(16 \%$ vs $21.9 \% \mathrm{p}=0.07)$ and by $2-3$ year follow up, the mortality rates were nearly identical $(23 \%$ vs $24.8 \% \mathrm{p}=0.65)$. Sustained long term benefits on survival have not been proven and this emphasizes the need for reporting of long-term outcomes with stent-grafting and careful documentation of the cause of failure of endovascular repair. We will discuss the advantages and disadvantages of stent-grafting by considering disease processes separately.

\subsection{Aneurysmal Diseases}

Historically, open repair of thoracic aneurysmal diseases is associated with a perioperative mortality rate ranging from $12 \%$ - $44 \%$, depending on the urgency of repair and patient co-morbidity [3]. Hence, stent-grafting may seem an attractive alternative with better outcomes in the shortterm. However, reports from high-volume centers report that elective open repair of thoracic aortic aneurysms with a short clamp time, intercostal re-implantation and selective atriofemoral bypass can be achieved with an operative mortality of $4 \%-5 \%$, stroke rates of $\sim 2.5 \%$ and paraplegia rates of $1.5 \%$ - 3\% [4-6]. Hence, prima facie, it would appear that open repair for thoracic aneurysmal disease can be undertaken with similar early outcomes to TEVAR if undertaken in high-volume centers. Since thoracic aortic aneurysms expand at $0.14-0.19 \mathrm{~cm} /$ year on average, slower than abdominal aortic aneurysms, at least 5 years is required to assess long-term efficacy of TEVAR in adequately excluding the aneurysm [7]. Our series which had a mean follow up of 3.6 years and included 32 patients with aneurysmal disease is inadequate to assess this. The series with the longest follow up of stent-grafting for aneurysmal disease is from Stanford. Survival at 1,5 and 8 years was $82 \%, 49 \%$ and $27 \%$ respectively [8]. Of note however, is that of the 75 deaths reported in this cohort, there were 10 fatal aortic ruptures which implies a significant $13 \%$ mortality from failure to adequately exclude the aneurysm in the long-term. In our cohort of 95-treated patients and 17 deaths, we had 2 confirmed deaths related to aortic pathology. Family consent for autopsy was not forthcoming in some cases and hence the true number of deaths from aortic pathology is probably under-estimated. Another consideration with longerterm follow up will be reinterventions. In our cohort we treated 13 endoleaks over the average follow-up of 3.6 years. In the Stanford series, the incidence of endoleaks was 33\% by 8 years and re-intervention was required in $22 \%$ of the patients by 8 years [2]. The need for reintervention related to the index pathology after open repair 
of thoracic aneurysms is negligible [9].

\subsection{Aortic Dissection}

Data from the international Registry of Aortic Dissection (IRAD) supports the use of TEVAR for dissection showing a 7\% in-hospital mortality with TEVAR vs 32\% with open surgery $(p<0.01)$ [10]. Given the high mortality of open surgery, TEVAR is the primary treatment for dissection although its role in uncomplicated dissection is controversial. In our cohort, we treated 35 patients for dissection and/or acute aortic syndromes. Nine of these interventions were for uncomplicated dissections. While medical therapy alone for uncomplicated dissections is associated with $84 \%$ survival at one year, mortality is $30 \%-50 \%$ at 5 years and at 4 years $20 \%$ - $50 \%$ will experience delayed expansion of the false lumen $[3,11]$. False aneurysms in a dissected aorta can grow significantly faster than degenerative aneurysms of an undissected aorta and the risk of rupture is greater at smaller aortic diameters. Hence it is conceptually attractive to use TEVAR to induce false lumen thrombosis and effect aortic remodelling by arresting false lumen enlargement despite the lack of an indication for urgent intervention $[12,13]$. The recently published INvestigation of STEnt Grafts in Patients with Type B Aortic Dissection (INSTEAD) trial reported improved aortic remodelling in chronic uncomplicated type B dissection with TEVAR compared to medical therapy (91\% vs 19\% false lumen thrombosis) but equivalent survival at 2 years (94\% vs 97\%) [14]. We will report clinical outcomes as well as aortic remodelling outcomes in this subgroup of patients when further follow-up is available.

\subsection{Traumatic Aortic Transection}

Traumatic aortic transection is associated with negligible survival without intervention [15]. Historically, the mortality associated with open repair of traumatic aortic transection was 32\% and a third of deaths occurred before surgical repair [16]. It is conceptually attractive to utilize TEVAR in this setting to exclude the aortic pathology expeditiously without thoracotomy and aortic clamping in a patient who may have multiple rib fractures, pulmonary and cardiac contusions. TEVAR has been increasingly applied in the trauma setting and has been associated with lower mortality when compared to traditional open repair [17]. Our series included 19 such patients. These patients, with an average age of 47 were significantly younger than the treated patients with degenerative thoracic aneurysms (average age 68) or aortic dissection (average age 62). Implanting stent-grafts, which have been designed to have a durability of 10 years [3], in relatively young patients will require vigilant follow up and reporting since patients in this group may live long enough to develop unique complications. As the thoracic aorta normally enlarges with age [18], this subgroup of patients may require re-interventions remote from the initial procedure. This is especially pertinent since these devices are frequently deployed over the subclavian artery in the trauma setting and minimally oversized to prevent "bird beaking" with infolding and sudden aortic obstruction. While TEVAR is arguably the standard of care in treating traumatic aortic injuries, the vascular specialist has to be cognizant of the potential need for re-intervention as these patients may be expected to live decades with their device.

\subsection{Marfan Patients}

The Marfan patient group is worthy of additional discussion. We treated 4 Marfan patients (3 for dissection and one for aneurysm). Results in this cohort are particularly interesting since stent-graft data is relatively sparse. Dissection or rupture of the thoracic aorta is the leading cause of late death after successful aortic root replacement in Marfan patients [19] and hence the potential utility of TEVAR in this setting is particularly pertinent. While the average age for patients with type $\mathrm{B}$ dissection is 65 years [3], Marfan patients presenting with dissection are typically younger and therefore the durability of TEVAR becomes a greater consideration. Of our three patients with Marfan's syndrome presenting with dissection, one presented with a complicated dissection (left renal malperfusion and aneurysmal degeneration to $53 \mathrm{~mm}$ ) while the second and third had uncomplicated dissections. The fourth Marfan patient presented with a 50-mm thoracic aneurysm. Except for an embolization of the left subclavian artery for a type II endoleak after the index procedure, none of these patients have required reintervention with an average follow up of $4.4 \pm 1.3$ years. Our experience in this patient group is favourable compared to other reports. TEVAR is not currently recommended for patients with Marfan syndrome by some authors [3] due to concerns that the weakened aortic wall cannot withstand radial forces exerted by the graft and will continue to expand resulting in type I endoleak. A six-patient series from Germany of TEVAR for descending aortic dissection in Marfan patients (mean age 33) with mean follow up of 51 months (4.25 years) reported that 3 patients required open conversion at 12, 22 and 43 months after an initially successful procedure for enlarging pseudoaneurysms [20]. Another small series of 7 patients raised similar concerns. In this series, stent-grafts were deployed to arrest aneurysmal degeneration in Marfan patients with chronic dissections. The thoracic aorta continued to dilate at an alarming average of $7 \mathrm{~mm}$ per year despite successful TEVAR of the entry tear and thrombosis of the false lumen [21]. However, the apparently 
poor durability of TEVAR in the Marfan group needs to be weighed against the risks of open repair, especially in acute presentations. TEVAR in Marfan patients may be best utilized as a bridge to definitive open surgical repair and may not be indicated at all in stable, asymptomatic patients.

\section{Conclusion}

TEVAR has emerged as the treatment modality of choice in patients presenting acutely with aortic catastrophes such as traumatic aortic transection, complicated type B dissection and ruptured aneurysms [22-24]. Emergency open repair of thoracic aortic disease is universally associated with high short-term mortality. The desire to see more patients survive to hospital discharge will mean that few surgeons will choose open repair over TEVAR in the emergency setting. This will be at the expense of increased re-interventions and possibly equivalent longterm outcomes as well as the potential for incomplete exclusion of the pathology, especially for ruptured aneurysmal disease [24]. The situations where more equipoise exists include elective repair of asymptomatic thoracic aortic aneurysm where TEVAR may not be superior to open repair and has an unproven durability. Another area requiring further study is the role of TEVAR in treating uncomplicated type B aortic dissection where improved aortic remodelling with stent-grafting has not translated into improved clinical outcomes [14]. While long term follow up from the INSTEAD investigators will be helpful in this regard, this trial is underpowered to provide any definitive answers and results of additional studies such as the Acute Dissection Stent-Grafting or Best Medical Treatment (ADSORB) study will inform practice. The utility of TEVAR in Marfan patients will require further clarification since these patients may be particularly prone to complications secondary to the radial forces exerted by the stent-graft. Publication of outcomes, especially longterm outcomes from groups around the globe will help define the durability of stent-grafts, especially beyond 10 years and this will aid in appropriate patient selection.

\section{Acknowledgements}

We would like to thank Ms Julie Jenkins and the Department of Vascular Surgery vascular staff for all their assistance in maintaining our database.

\section{REFERENCES}

[1] M. D. Dake, et al., "Transluminal Placement of Endovascular Stent-Grafts for the Treatment of Descending Thoracic Aortic Aneurysms," The New England Journal of Medicine, Vol. 331, No. 26, 1994. pp. 1729-1734. doi:10.1056/NEJM199412293312601

[2] D. Cheng, et al., "Endovascular Aortic Repair versus
Open Surgical Repair for Descending Thoracic Aortic Disease: A Systematic Review and Meta-Analysis of Comparative Studies," Journal of the American College of Cardiology,” Vol. 55, No. 10, 2010, pp. 986-1001. doi:10.1016/j.jacc.2009.11.047

[3] M. A. Coady, et al., "Surgical Management of Descending Thoracic Aortic Disease: Open and Endovascular Approaches-A Scientific Statement from the American Heart Association,” Circulation, Vol. 121, No. 25, 2010, pp. 2780-2804. doi:10.1161/CIR.0b013e3181e4d033

[4] J. S. Coselli, et al., "Results of Contemporary Surgical Treatment of Descending Thoracic Aortic Aneurysms: Experience in 198 Patients,” Annals of Vascular Surgery, Vol. 10, No. 2, 1996, pp. 131-137. doi:10.1007/BF02000756

[5] J. S. Coselli, et al., "Left Heart Bypass during Descending Thoracic Aortic Aneurysm Repair Does Not Reduce the Incidence of Paraplegia,” The Annals of Thoracic Surgery, Vol. 77, No. 4, 2004. pp. 1298-1303. doi:10.1016/j.athoracsur.2003.10.033

[6] K. Minatoya, et al., "Replacement of the Descending Aorta: Recent Outcomes of Open Surgery Performed with Partial Cardiopulmonary Bypass," The Journal of Thoracic and Cardiovascular Surgery, Vol. 136, No. 2, 2008, pp. 431-435. doi:10.1016/j.jtcvs.2008.03.034

[7] R. K. Greenberg, et al., "Contemporary Analysis of Descending Thoracic and Thoracoabdominal Aneurysm Repair: A Comparison of Endovascular and Open Techniques,” Circulation, Vol. 118, No. 8, 2008, pp. 808-817. doi:10.1161/CIRCULATIONAHA.108.769695

[8] P. Demers, et al., "Midterm Results of Endovascular Repair of Descending Thoracic Aortic Aneurysms with FirstGeneration Stent Grafts,” The Journal of Thoracic and Cardiovascular Surgery, Vol. 127, No. 3, 2004. pp. 664673. doi:10.1016/j.jtcvs.2003.10.047

[9] K. Minatoya, et al., "Replacement of the Descending Aorta: Recent Outcomes of Open Surgery Performed with Partial Cardiopulmonary Bypass," The Journal of Thoracic and Cardiovascular Surgery, Vol. 136, No. 2, 2008. pp. 431-435. doi:10.1016/j.jtcvs.2008.03.034

[10] T. Suzuki, et al., "Clinical Profiles and Outcomes of Acute Type B Aortic Dissection in the Current Era: Lessons from the International Registry of Aortic Dissection (IRAD)," Circulation, Vol. 108, Suppl. 1, 2003, pp. II312II317. doi:10.1161/01.cir.0000087386.07204.09

[11] M. Kato, et al., "Determining Surgical Indications for Acute Type B Dissection Based on Enlargement of Aortic Diameter during the Chronic Phase," Circulation, Vol. 92, Suppl. 9, 1995, pp. 107-112. doi:10.1161/01.CIR.92.9.107

[12] M. D. Dake, et al., "Endovascular Stent-Graft Placement for the Treatment of Acute Aortic Dissection," The New English Journal of Medicine, Vol. 340, No. 20, 1999, pp. 1546-1552. doi:10.1056/NEJM199905203402004

[13] C. A. Nienaber, et al., "Nonsurgical Reconstruction of Thoracic Aortic Dissection by Stent-Graft Placement," The New English Journal of Medicine, Vol. 340, No. 20, 1999, pp. 1539-1545.

doi:10.1056/NEJM199905203402003 
[14] C. A. Nienaber, et al., "Randomized Comparison of Strategies for Type B Aortic Dissection: The INvestigation of STEnt Grafts in Aortic Dissection (INSTEAD) Trial,” Circulation, Vol. 120, No. 25, 2009, pp. 2519-2528. doi:10.1161/CIRCULATIONAHA.109.886408

[15] L. F. Parmley, et al., "Nonpenetrating Traumatic Injury of the Aorta," Circulation, Vol. 17, No. 6, 1958, pp. 10861101. doi:10.1161/01.CIR.17.6.1086

[16] U. O. Von Oppell, et al., "Traumatic Aortic Rupture: Twenty-Year Metaanalysis of Mortality and Risk of Paraplegia,” The Annals of Thoracic Surgery, Vol. 58, No. 2, 1994, pp. 585-593. doi:10.1016/0003-4975(94)92270-5

[17] F. H. W. Jonker, et al., "Trends and Outcomes of Endovascular and Open Treatment for Traumatic Thoracic Aortic Injury,” Journal of Vascular Surgery, Vol. 51, No. 3, 2010, pp. 565-571. doi:10.1016/j.jvs.2009.10.046

[18] G. P. Clagett, “EVAR, TEVAR, FEVAR, Too Far?” Perspectives in Vascular Surgery and Endovascular Therapy, Vol. 20, No. 2, 2008, pp. 115-119. doi:10.1177/1531003508319379

[19] V. L. Gott, et al., "Replacement of the Aortic Root in Patients with Marfan's Syndrome,” The New England
Journal of Medicine, Vol. 340, No. 17, 1999, pp. 13071313. doi:10.1056/NEJM199904293401702

[20] H. Ince, et al., "Stent-Grafts in Patients with Marfan Syndrome," Journal of Endovascular Therapy, Vol. 12, No. 1, 2005, pp. 82-88. doi:10.1583/04-1415MR.1

[21] I. M. Nordon, et al., "Endovascular Management of Chronic Aortic Dissection in Patients with Marfan Syndrome,” Journal of Vascular Surgery, Vol. 50, No. 5, 2009, pp. 987-991. doi:10.1016/j.jvs.2009.05.056

[22] R. P. Cambria, et al., “A Multicenter Clinical Trial of Endovascular Stent Graft Repair of Acute Catastrophes of the Descending Thoracic Aorta," Journal of Vascular Surgery, Vol. 50, No. 6, 2009, pp. 1255-1264, e1-e4.

[23] F. H. W. Jonker, et al., "Outcomes of Endovascular Repair of Ruptured Descending Thoracic Aortic Aneurysms," Circulation, Vol. 121, No. 25, 2010, pp. 2718-2723. doi:10.1161/CIRCULATIONAHA.109.908871

[24] F. H. Jonker, et al., "Meta-Analysis of Open versus Endovascular Repair for Ruptured Descending Thoracic Aortic Aneurysm,” Journal of Vascular Surgery, Vol. 51, No. 4, 2010, pp. 1026-1032, 1032 e1-1032 e2. 